\title{
Effects of lesions of the amygdala, pyriform cortex, and stria terminalis on two types of exploration by rats
}

\author{
DANIEL COULOMBE and NORMAN WHITE \\ McGill University, Montreal, Quebec H3A 1BI, Canada
}

\begin{abstract}
Bilateral lesions were made in three groups of rats, selectively destroying the corticomedial amygdala, the pyriform cortex, or the dorsal stria terminalis. During Phase 1 of the experiment, the behavior of each rat was observed in an open-field apparatus for 4 consecutive days for 5 min per day. This phase permitted an evaluation of exploration that occurs when a rat is forced into contact with novelty. During Phase 2, a novel object was placed in the center of the open field and the procedure was repeated for 4 more days. This phase permitted an evaluation of the exploration that occurs when a rat can interact voluntarily with novelty. Lesions of the corticomedial amygdala increased contact with novelty during Phase 1 and increased exploration of the novel object during Phase 2. Stria terminalis lesions produced the same pattern, except that contact and exploration were decreased. Pyriform lesions decreased exploration only during Phase 2 . These data show that the effect of lesions of the amygdala and related structures on exploration are different when different types of exploration are measured. The role of the amygdala and its afferent and efferent neural connections in mediating the two types of exploration studied is discussed.
\end{abstract}

Although exploration by rats has been studied extensively at the behavioral level (Barnett, 1963; Barnett \& Cowan, 1976; Fowler, 1965; Halliday, 1968; Lester, 1968; McReynolds, 1962; Russell, 1973), relatively little is known about the affective processes and the related neural substrates which mediate this behavior. Exploration is usually discussed in relation to emotionality in general, and to such anthropomorphic concepts as "fear" and "curiosity" in particular (Blanchard \& Blanchard, 1972; Blanchard, Kelley, \& Blanchard, 1974; Montgomery, 1955; Montgomery \& Monkman, 1955). This notion has led several investigators to study the role of the amygdala in exploration. The studies to date have all examined the effects of lesions of this structure on exploration.

Corman, Meyer, and Meyer (1967) found that rats with bilateral lesions of the basolateral amygdala exhibited slightly (but not significantly) more locomotor activity than normal rats. McIntyre and Stein (1973) reported that bilateral destruction of the central nucleus of the amygdala

This research was supported by a grant from the National Research Council of Canada to $\mathrm{N}$. White, and by a grant from FCAC, Quebec Ministry of Education. The research formed the basis of a thesis for the MA degree by D. Coulombe. We acknowledge the use of the facilities of the computer-based laboratory, Department of Psychology, McGill University. We are especially thankful for the critical comments of A. Ettenberg and R. Beninger. Requests for reprints should be sent to Daniel Coulombe, Department of Psychology, McGill University, 1205 McGregor Avenue, Quebec, H3A 1B1, Canada. produced no change in levels of locomotor activity and exploration. White and Weingarten (1976) found that satiated rats with bilateral lesions of the basolateral nucleus and adjacent pyriform cortex explored more than normal rats when exposed to novel visual and olfactory stimuli. However, in the same study, similar lesions produced decreases in exploration in food-deprived animals.

These results are difficult to interpret for several reasons. First the studies cited have not all taken into account the several different types of exploration that have been identified on the behavioral level. Berlyne (1960) described three distinct types of exploratory behavior in rats and the operational conditions associated with each: (1) Inspective exploration occurs when a rat is forced into contact with a novel situation or with novel stimuli. These conditions prevailed in the experiments reported by Corman et al. (1967) and by White and Weingarten (1976). In both cases, increases in the behavioral measures were observed following amygdaloid destruction. (2) Inquisitive exploration occurs when a rat in a familiar environment is given an opportunity to explore a novel area or stimulus object voluntarily. This condition prevailed in the study by McIntyre and Stein (1973), who did not observe an increase in exploration following amygdaloid destruction. (3) The third type of exploration generally occurs when rats are food deprived, and may be presumed to be searching for food. White 
and Weingarten (1976) found that this type of exploration was decreased by amygdaloid lesions.

A second difficulty in interpreting data on the effects of amygdaloid lesions on exploration lies in the probable functional differentiation within the different parts of the amygdala with respect to their influence on this behavior. In the three studies discussed above, "amygdaloid lesions" were in fact lesions involving anatomically different parts of the amygdala: the basolateral nucleus (Corman et al., 1967), the central nucleus (McIntyre \& Stein, 1973), and the corticomedial nucleus and pyriform cortex (White \& Weingarten, 1976). It ' seems likely that these differences might also have contributed to the confusing nature of the results.

In the present study, we examined the effects of localized lesions on two of the three identified types of exploration. Anatomically, we sought to determine whether two of the major connections between the amygdala and other limbic structures mediate the neural activity which accompanies exploratory behavior by making bilateral lesions in the pyriform cortex or the dorsal stria terminalis in two groups of rats. In a third group, we destroyed the corticomedial amygdala, through which both of these pathways pass.

\section{METHOD}

\section{Subjects}

Forty-four male hooded rats, weighing $250-300 \mathrm{~g}$ at the time of surgery were housed individually in plastic laboratory cages under a 12-h light/12-h dark cycle. Food pellets and water were freely available.

\begin{abstract}
Apparatus
The test apparatus was a Plexiglas box measuring $60 \times 60$ $\times 30 \mathrm{~cm}$. Three walls were opaque; the front wall was clear to permit observation of the rats by an observer in the room. The room was dark, and the test apparatus was dimly lit by an indirect $60 \mathrm{~W}$ bulb. The object used as the novel stimulus was a black wooden block, measuring $5 \times 4 \times 4 \mathrm{~cm}$. Behavioral observations were recorded using a PDP-11 computer, which received impulses from an array of 10 buttons mounted on a small control box. Each button corresponded to a behavior category. Pressing any button indicated that a bout of the behavior associated with that button had begun; pressing a second button indicated that the rat had initiated another type of behavior. A program computed the total duration of each behavior.
\end{abstract}

\section{Behavior Categories}

A total of seven categories of behavior were recorded during the behavior observation periods. The categories are described in Table 1.

\section{Procedure}

All subjects underwent standard stereotaxic surgery under sodium pentobarbital anesthesia $(60 \mathrm{mg} / \mathrm{kg})$, supplemented with chloral hydrate $(400 \mathrm{mg} / \mathrm{ml})$ as needed. Bilateral electrolytic lesions were produced stereotaxically by inserting a $.2 \mathrm{~mm}$ diameter monopolar stainless steel electrode, insulated with Formvar except for $.5 \mathrm{~mm}$ at the tip, at the following coor-
Table 1

Categories for Behavior Observation

\begin{tabular}{cl}
\hline $\begin{array}{l}\text { Exploration } \\
\text { rearing }\end{array}$ & $\begin{array}{l}\text { rat rears on hind legs, usually accom- } \\
\text { panied by sniffing } \\
\text { rat sits motionless and sniffs } \\
\text { rniffing } \\
\text { walking } \\
\begin{array}{l}\text { rat walks or shifts its position so as } \\
\text { to involve all four limbs, usually } \\
\text { accompanied by sniffing } \\
\text { (Phase 2) }\end{array}\end{array}$ \\
$\begin{array}{l}\text { Nonexploration } \\
\text { grooming }\end{array}$ & rat sniffs or manipulates object \\
sitting motionless & $\begin{array}{l}\text { rat licks, scratches, or cleans any part } \\
\text { of its body } \\
\text { rat sits relaxed and motionless, tail } \\
\text { on surface of floor } \\
\text { rat lies relaxed with abdomen on } \\
\text { floor of cage }\end{array}$ \\
\hline
\end{tabular}

dinates (de Groot, 1959): the corticomedial amygdala (CMA): $5.1, \pm 3.5,-3.5$; the pyriform cortex (PYR): 5.1, \pm 6.5 , -3.5 ; the stria terminalis (ST): $4.8, \pm 4.0,1.0$. To produce the lesions, a $1 \mathrm{~mA}$ circuit was closed for $20 \mathrm{sec}$ in the case of CMA and PYR lesions and for $10 \mathrm{sec}$ in the case of ST lesions, between the intracranial anode and a cathode fixed to the ear-bars of the stereotaxic instrument. The control animals were anesthesized without other treatment. After surgery, all animals were returned to their respective home cages and allowed to recover.

The first of the eight daily behavioral observation sessions was carried out 5 to 7 days after the lesions were made. All testing occurred during the last $2 \mathrm{~h}$ of the light phase and the first $2 \mathrm{~h}$ of the dark cycle. There were no differences in the scores obtained during the light and dark test periods; however, testing was organized so that half of the rats in each group were observed in each period. Immediately before testing each rat, the inside of the test box was wiped clean with a $50 \%$ alcohol solution to eliminate odor cues (Whittier \& McReynolds, 1965). Phase 1 of the experiment lasted for 4 days. On each of these days, each subject was placed in a corner of the empty test apparatus, and behavior observations were made for $5 \mathrm{~min}$. Phase 2 also lasted for 4 days, and the procedure was identical, except that the novel object was placed in the middle of the floor of the test box.

After the completion of these tests, the animals were given an overdose of sodium pentobarbital and perfused intracardially with a $.85 \%$ saline solution and $10 \%$ Formalin. Their brains were removed and fixed in $10 \%$ Formalin, after which the lesions were reconstructed from $40 \mu$ thionin-stained frozen sections.

\section{RESULTS}

Histological examination of the brains revealed that 10 animals sustained bilateral pyriform cortex lesions. The pyriform cortex (Figure 1) was extensively destroyed, with slight damage to the basolateral and cortical nuclei of the amygdala. Four animals sustained bilateral lesions of the corticomedial amygdala, destroying mainly the cortical and medial nuclei. These lesions are shown in Figure 2. Finally, the stria terminalis was damaged bilaterally in six rats. Figure 3 shows that these 


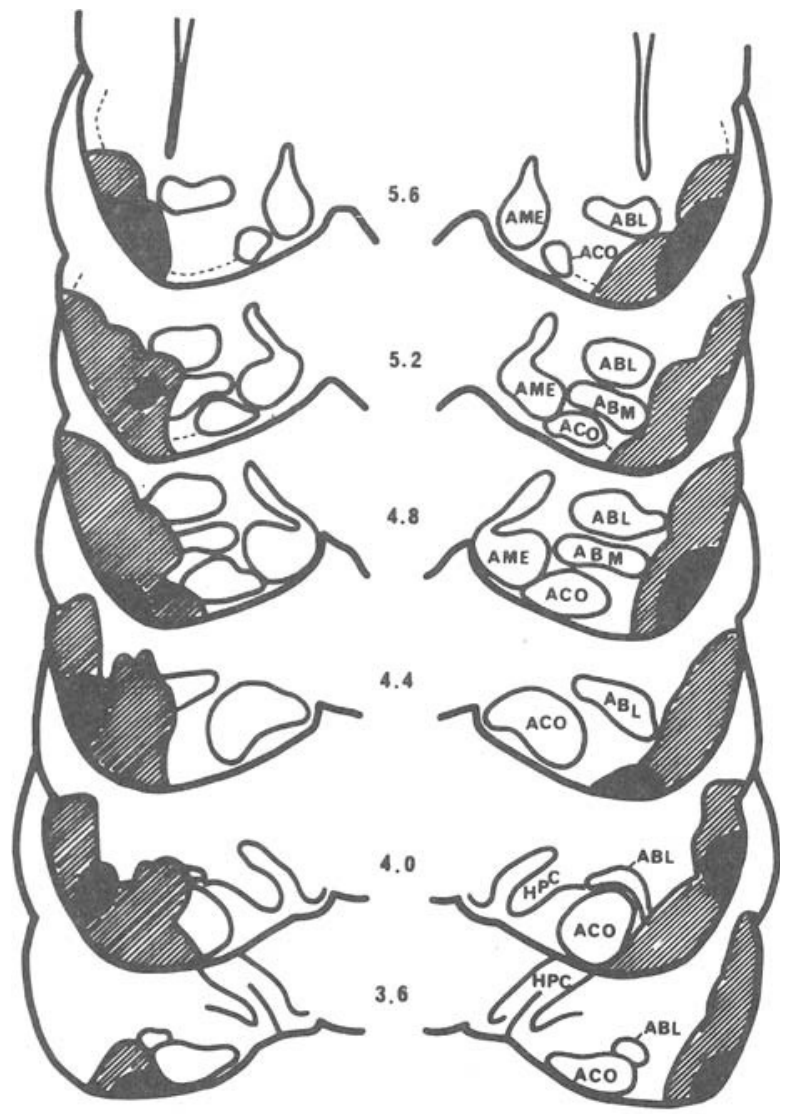

Figure 1. Area of bilateral pyriform cortex lesions observed in 10 rats. The striped area shows the maximum extent of the lesions, and the dark area shows the extent of the smallest lesion observed. A-P coordinates according to Pellegrino and Cushman (1967) appear on the midline. Abbreviations: ABM, basomedial nucleus; ABL, basolateral nucleus; ACO, cortical nucleus; AME, medial nucleus; HPC, hippocampus.

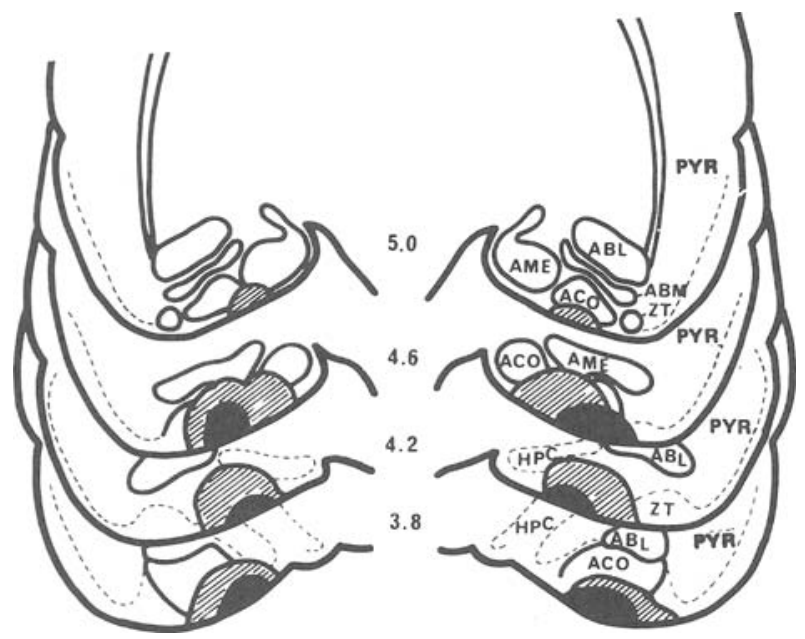

Figure 2. Area of bilateral corticomedial amygdaloid lesions observed in four rats. The striped area shows the maximum extent of the lesions, and the black area shows the smallest extent of the damage observed. Abbreviations: PYR, pyriform cortex; ZT, transition zone. All other abbreviations are as in Figure 1. lesions destroyed a section of the stria terminalis, parts of the dorsal putamen and internal capsule, the most lateral parts of the fimbria of the hippocampus, and parts of the reticular, ventral, and ventrodorsal nuclei of the thalamus.

Assessment of the behavioral data included an analysis of the sniffing, walking, and rearing scores, of a total exploration score made up of the sum of these three component behaviors, in Phases 1 and 2 of the study, and analysis of the object exploration score in Phase 2. Although it contributed to the total exploration score, there were no significant changes in the amount of walking, so this behavior is not discussed further. Similarly, there were no significant changes in the nonex-

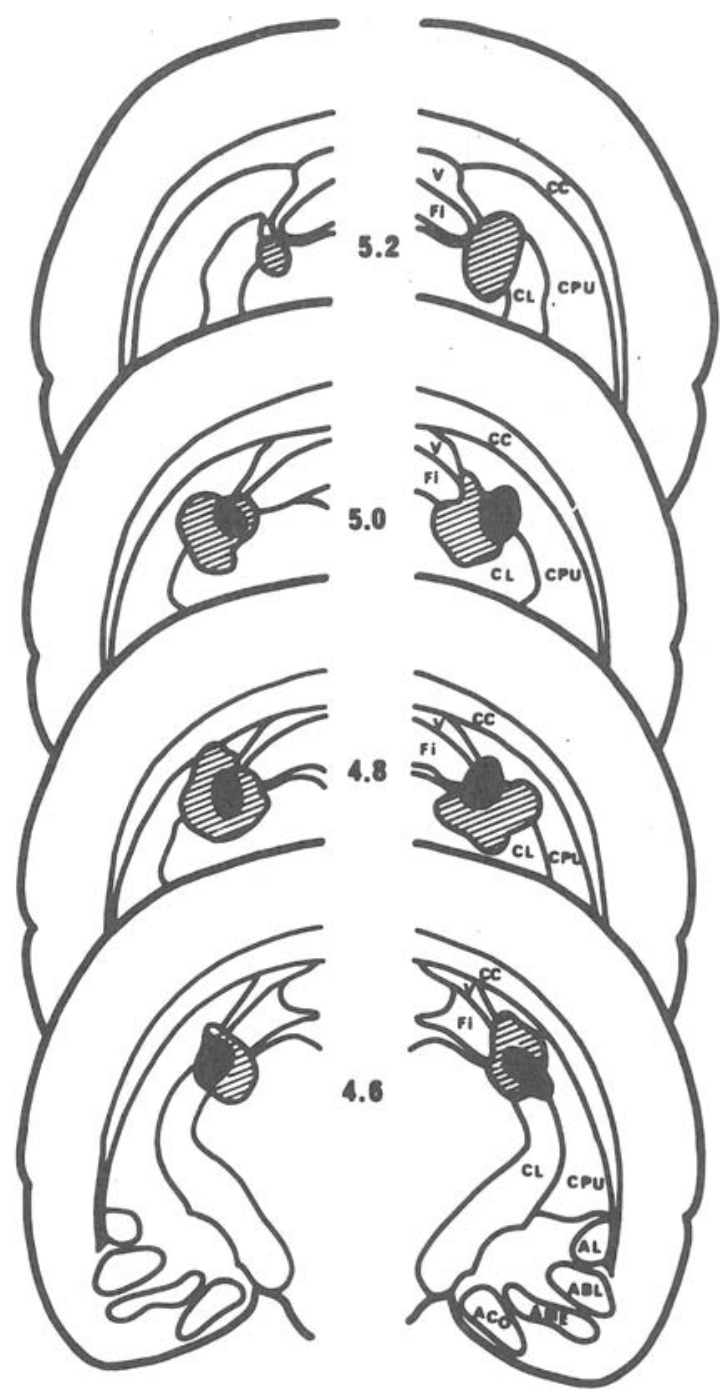

Figure 3. Area of bilateral stria terminalis lesions observed in six rats. The striped area shows the maximum extent of lesion, and the black area shows the smallest extent of the damage observed. Abbreviations: AL, lateral nucleus of amygdala; $\mathbf{C C}$, corpus callosum; CI, capsula interna; CPU, putamen; FI, fimbria of the hippocampus; $V$, ventricle. All other abbreviations are as in Figure 1. 


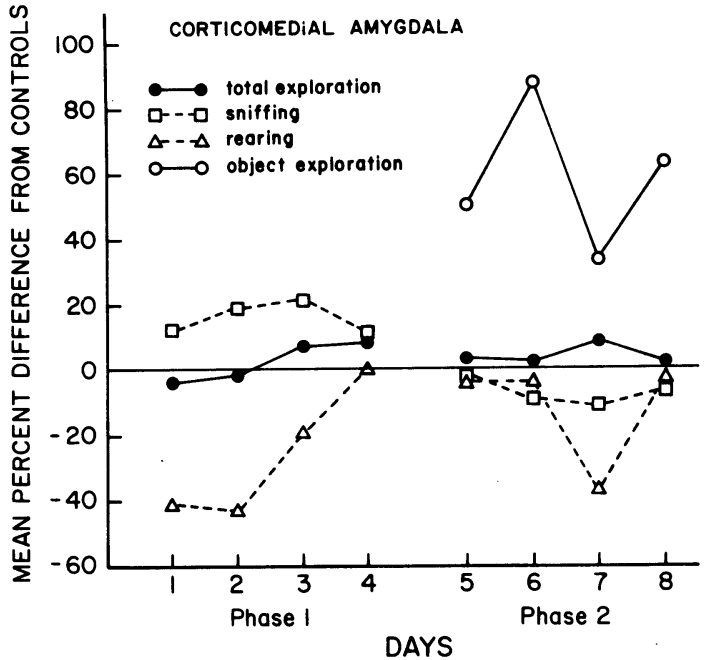

Figure 4. Behavioral data for rats with corticomedial amygdala lesions.

ploratory behaviors shown in Table 1 , so no data for these are presented. The day-by-day mean percent differences between the experimental and control groups for the behaviors that were affected by the lesions are shown in Figures 4, 5, and 6. The data were transformed using the arcsin square root procedure, and then the data for each phase of the study were evaluated with an analysis of variance for a split plot factorial design with groups of unequal size (Kirk, 1968). The main effects were groups and days, with days as a repeated measure. In cases where it was justified by the results of the overall analysis, further pairwise orthogonal multiple comparisons were made.

The lesions in the area of the corticomedial amygdala (Figure 4) did not produce a significant difference in total exploration in Phase $1[\mathrm{~F}(1,19)=$

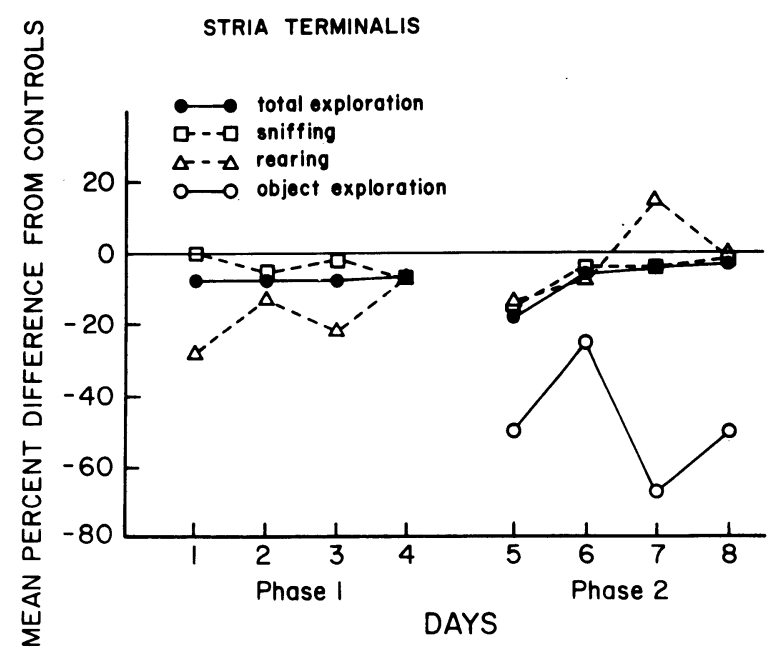

Figure 5. Behavioral data for rats with stria terminalis lesions.
$.29, \mathrm{p}=.4]$. However, as can be seen from the figure, this lack of difference was due to effects in opposite directions on sniffing and rearing. The CMA rats sniffed significantly more than the control rats $[\mathrm{F}(1,19)=4.5, \mathrm{p}<.05]$. Although there were no group differences in rearing $[F(1,19)=2.3$, $\mathrm{p}>.05]$, the interaction was significant $[F(3,57)=$ $4.1, \mathrm{p}=.01]$ so that an analysis of simple effects was appropriate. This analysis showed that the CMA rats reared significantly less than control rats on Day $1[F(1,63)=4.6, p<.05]$ and on Day 2 $[F(1,63)=5.6, p<.05]$. During Phase 2, there were no significant differences in the total exploration, sniffing, or rearing scores. However, the CMA rats explored the novel object significantly more than controls during this phase of the experiment $[F(1,26)=4.9, p<.05]$.

For the rats in the stria terminalis group (Figure 5 ), although there was no difference in sniffing and rearing, the total exploration score was significantly below that for the rats in the control group during Phase $1[\mathrm{~F}(1,21)=5.9, \mathrm{p}<.02]$. During Phase 2, there was no significant difference between the two groups on this score $[\mathrm{F}(1,28=.72, \mathrm{p}=.41]$. However, in the latter case, the interaction was significant $[F(3,84)=5.6, p<.002]$, and the analysis of simple effects revealed that there was a significant difference between the groups on Day 1 $[\mathrm{F}(1,90)=9.2, \mathrm{p}<.01]$. During this phase, the stria terminalis rats explored the novel object significantly less than the controls $[F(1,28)=4.9$, $\mathrm{p}<.01]$.

Lesions of the pyriform cortex (Figure 6) produced no significant difference in sniffing, rearing, or total exploration during Phase $1[\mathrm{~F}(1,17)=.24$, $\mathrm{p}=$.37]. During Phase 2, the total exploration score was significantly lower in the PYR rats than in controls $[\mathrm{F}(1,32)=4.5, \mathrm{p}<.04]$, and the rats

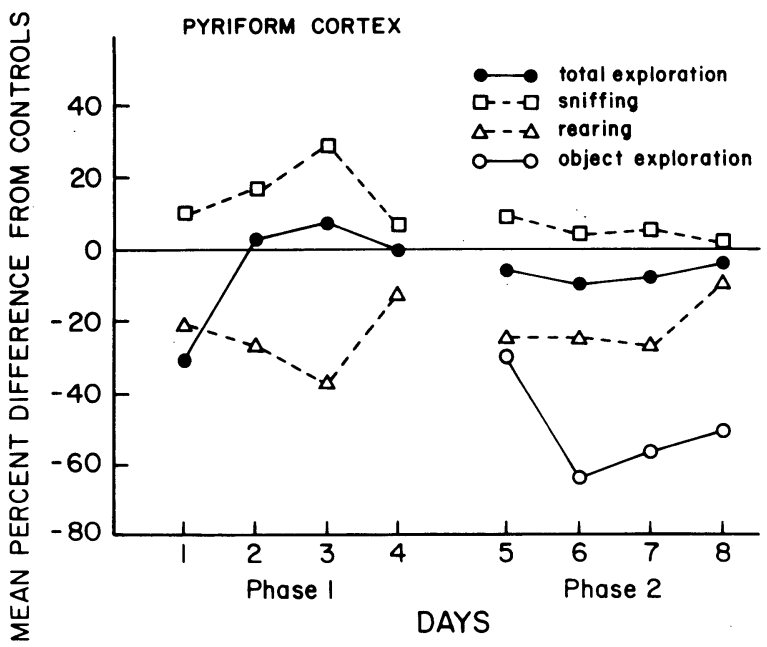

Figure 6. Behavioral data for rats with pyriform cortex lesions. 
with pyriform lesions explored the object significantly less than control rats $[\mathrm{F}(1,32)=8.7$, $\mathrm{p}<.006]$.

\section{DISCUSSION}

In Phase 1, the rats were exposed to a novel environment from which there was no escape. These conditions fulfilled the requirements for inspective exploration according to Berlyne (1960) or novelty-adjustive exploration according to McReynolds (1962). In Phase 2, inspective exploration continued to occur, and, in addition, exploration of the object during this phase provided a measure of inquisitive (Berlyne, 1960) or novelty-seeking (McReynolds, 1962) exploration, as the rats could approach or avoid the novel object voluntarily. The data for the rats in the three lesion groups confirm the hypothesis that lesions of different brain areas related to the amygdala produce different effects on these two types of exploration.

Lesions of the corticomedial amygdala and surrounding tissue (Figure 4) had no effect on the overall exploration score in Phase 1 , but did affect two of the components of total exploration, sniffing, and rearing, increasing the former and decreasing the latter. Misshin, Bouchon, and Ropartz (1976) have suggested that sniffing of particular objects in the environment represents exploration, while rearing is indicative of a tendency to escape. This interpretation is supported by the increase in exploration of the novel object produced by these lesions in Phase 2. Other workers who have examined rats' responses to novelty of various kinds, have used the term "neophobia" to describe this type of behavior, and Nachman and Ashe (1974) have suggested that amygdaloid lesions reduce neophobia, a finding which is apparently confirmed by the data presented here. Since lesions of the corticomedial area increased the rats' tendency to interact with novelty in the two experimental situations in this study, it seems reasonable to conclude that this area of the amygdala normally functions to suppress these approach responses. This conclusion is consistent with the views of amygdaloid function expressed by other authors (Goddard, 1964; Kaada, 1972; White \& Weingarten, 1976).

In exerting this control over exploration and other approach behaviors, the corticomedial area must function together with other brain areas as part of a neural circuit. We studied the effects of lesions in two of the neural structures which may serve as the links between the amygdala and these other areas. Lesions of the stria terminalis (Figure 5) decreased exploration in Phase 1. This effect was present at the beginning of, but disappeared during, Phase 2 and was simultaneous with a decrease in exploration of the novel object. Thus, while CMA lesions increased the tendency to approach or interact with novelty, ST lesions decreased the rats' tendency to interact with novelty. If one assumes that the ST is an important link between the amygdala and the hypothalamus in the control of exploration. as it is for other behaviors (Elwers \& Critchlow, 1960; Gloor, 1960; Nauta, 1963; White \& Fisher, 1969), then it seems likely that this pathway relays an inhibitory action from the hypothalamus to the amygdala. Hilton and Zbrozyna (1963) have demonstrated that the role of the amygdala in producing the defensive response in cats (Hess, 1957) is biased by a diencephalic influence which acts via the stria terminalis. It is possible that exploration in response to novelty in rats is a behavior homologous with the defensive response in cats. If so, the present data suggest a similar role for the stria terminalis in the amygdalo-diencephalic relationships involved in producing behaviors related to "emotionality" in the two species.

Pyriform cortex lesions (Figure 6) affected the rats' behavior only in Phase 2 of the experiment. During this phase, the rats avoided the novel object, and their total exploratory activity was also reduced. This pattern of responding suggests that, in contrast to the CMA lesions, the PYR lesions had a specific effect on neophobia. As the pyriform cortex relays sensory input to the amygdala from the lateral olfactory tract (Lammers, 1972), it seems likely that the lesions eliminated, or partly eliminated, a source of input to the amygdala which is normally necessary for the inhibition of responses to novelty by that structure.

In summary, data from the present study and others strongly suggest that the corticomedial amygdala normally exerts a generally inhibitory influence on approach behaviors, including exploration. The CMA is influenced by the hypothalamus via the amygdaloid afferents in the stria terminalis (de Olmos \& Ingram, 1972; Renaud \& Hopkins, 1977; Turner \& Knapp, 1976), and it responds to the degree of novelty in the pattern of activity in these afferents. The CMA also appears to be influenced by patterns of activity from the pyriform cortex (de Olmos \& Ingram, 1972) that provide information about specific novel features of the environment. This input would cause the CMA to inhibit approach, producing neophobia.

\section{REFERENCES}

Barnett, S. A. The rat: A study in behavior. Chicago: Aldine, 1963.

Barnett, S. A., \& Cowan, P. E. Activity, exploration, curiosity and fear: An ethological study. International Scientific Review, 1976, 1, 43-62.

Berlyne, D. E. Conflict. arousal and curiosity. New York: McGraw-Hill, 196() . 
BLANCHARD, D. C., \& BLANChARD, R. J. Innate and conditioned reactions to threat in rats with amygdaloid lesions. Journal of Comparative and Physiological Psychology, 1972, 81, 281-290.

Blanchard, R. J., Kelley, M. J., \& Blanchard, D. C. Defensive reactions and exploratory behavior. Journal of Comparative and Physiological Psychology, 1974, 87, 1129-1133.

Corman, D. C., Meyer, P. M., \& Meyer, D. R. Open-field activity and exploration in rats with septal and amygdaloid lesions. Brain Research, 1967, 5, 469-476.

DE Groot, J. The rat forebrain in stereotaxic coordinates. Amsterdam: N. V. Noord-Hollandsche, 1959.

DE Olmos, J. S., \& Ingram, W. R. The projection field of the stria terminalis in the rat brain: An experimental study. Journal of Comparative Neurology, 1972, 146, 303-334.

ElWers, M., \& Critchlow, V. Precocious ovarian stimulation following hypothalamic and amygdaloid lesions in rats. American Journal of Physiology, 1960, 198, 381-385.

Fowler, H. Curiosity and exporatory behavior. New York: Macmillan, 1965.

GLoor, P. Amygdala. In J. Field (Ed.), Handbook of neurophysiology (Section 1, Vol. 2). Washington, D.C: American Physiological Society, 1960.

Goddard, G. V. Functions of the amygdala. Psychological Bulletin, 1964, 62, 89-109.

HAlliday, M. S. Exploratory behavior. In L. Weiskrantz (Ed.), Analysis of behavioral change. New York: Harper and Row, 1968.

HESS, W. R. The functional organization of the diencephalon. New York: Grune and Stratton, 1957.

Hilton, S. M., \& Zbrozyna, A. W. Amygdaloid region for defense reactions and its efferent pathway to the brain stem. Journal of Physiology, 1963, 165, 160-173.

KAADA, B. R. Stimulation and regional ablation of the amygdaloid complex with reference to functional representations. In B. E. Eleftheriou (Ed.), The neurobiology of the amygdala. New York: Plenum, 1972.

KIRK, R. E. Experimental design: Procedures for the behavioral sciences. Belmont: Brooks/Cole, 1968.

LAMmERS, H. J. The neural connections of the amygdaloid complex in mammals. In B. E. Eleftheriou (Ed.), The neurobiology of the amygdala. New York: Plenum, 1972.

LESTER, D. The effect of fear and anxiety on exploration and curiosity: Toward a theory of exploration. Journal of General Psychology, 1968, 79, 105-120.
McIntyre, M., \& Stein, D. G. Differential effects of one- vs. two-stage amygdaloid lesions on activity, exploration, and avoidance behavior in the albino rat. Behavioral Biology, 1973, 9, 451-465.

MCREYNoLDS, P. Exploratory behavior: A theoretical interpretation. Psychological Reports, 1962, 11, 311-318.

Misshin, R., Bouchon, R., \& Ropartz, P. Signification de certains paramètres comportementaux chez la souris placée dans un open-field. Physiology \& Behavior, 1976, 17, 767-770.

Montgomery, K. C. The relation between fear inducēd by novel stimulation and exploratory behavior. Journal of Comparative and Physiological Psychology, 1955, 48, 254-260.

Montgomery, K. C., \& Monkman, J. A. The relation between fear and exploratory behavior. Journal of Comparative and Physiological Psychology, 1955, 48, 132-136.

NaChman, M., \& Ashe, J. H. Effects of basolateral amygdala lesions on neophobia, learned taste aversions, and sodium appetite in rats. Journal of Comparative and Physiological Psychology, 1974, 87, 622-643.

NAUTA, W. J. H. Central nervous organization and the endocrine system. In E. V. Nalbandov (Ed.), Advances in neuroendocrinology. Urbana: University of Illinois Press, 1963.

Pellegrino, L. J., \& Cushman, A. J. A stereotaxic atlas of the rat brain. New York: Appleton-Century-Crofts, 1967.

Renaud, L. P., \& Hopkins, D. A. Amygdala afferents from the mediobasal hypothalamus: An electrophysiological and neuroanatomical study in the rat. Brain Research, 1977, 121, 201-213.

Russell, P. A. Relationships between exploratory behavior and fear: A review. British Journal of Psychology, 1973, 64, 417-433.

TuRner, B. H., \& KNAPP, M. E. Projections of the nucleus and tracts of the stria terminalis following lesions at the level of the anterior commissure. Experimental Neurology, 1976, 51, 468-479.

White, N., \& Fisher, A. E. Relationship between amygdala and hypothalamus in the control of eating behavior. Physiology \& Behavior, 1969, 4, 199-205.

White, N., \& Weingarten, H. Effects of amygdaloid lesions on exploration by rats. Physiology \& Behavior, 1976, 17, 73-79.

Whittier, J. L., \& MCReynolds, P. Persisting odors as a biasing factor in open-field research with mice. Canadian Journal of Psychology, 1965, 19, 224-230.

(Received for publication January 27, 1978; revision accepted March 16, 1978.) 